

\title{
Biotic regulation of non-limiting nutrient pools and coupling of biogeochemical cycles
}

\author{
Anne-Sophie Auguères, Michel Loreau
}

\section{To cite this version:}

Anne-Sophie Auguères, Michel Loreau. Biotic regulation of non-limiting nutrient pools and coupling of biogeochemical cycles. Ecological Modelling, 2016, 334, pp.1-7. 10.1016/j.ecolmodel.2016.04.016 . hal-01444078

\author{
HAL Id: hal-01444078 \\ https://hal.science/hal-01444078
}

Submitted on 21 Feb 2022

HAL is a multi-disciplinary open access archive for the deposit and dissemination of scientific research documents, whether they are published or not. The documents may come from teaching and research institutions in France or abroad, or from public or private research centers.
L'archive ouverte pluridisciplinaire HAL, est destinée au dépôt et à la diffusion de documents scientifiques de niveau recherche, publiés ou non, émanant des établissements d'enseignement et de recherche français ou étrangers, des laboratoires publics ou privés. 


\title{
Biotic regulation of non-limiting nutrient pools and coupling of biogeochemical cycles
}

\author{
Anne-Sophie Auguères*, Michel Loreau \\ Centre for Biodiversity Theory and Modelling, Theoretical and Experimental Ecology Station, CNRS and Paul Sabatier University, 09200 Moulis, France
}

\section{A R T I C L E I N F O}

Article history:

Received 27 December 2015

Received in revised form 16 April 2016

Accepted 19 April 2016

Keywords:

Anthropogenic impacts

Biogeochemical cycles

Nutrient cycling

Nutrient limitation

Regulation

Resource access limitation

\begin{abstract}
A B S T R A C T
Anthropogenic activities heavily affect biogeochemical cycles at global scales; thus it is critical to understand the degree to which these cycles can be regulated by organisms. Autotrophs can regulate nutrient abundance through resource consumption, but their growth should not be affected by changes in the supply of non-limiting nutrients. Here we present a model where autotrophs consume two nutrients - one limiting and one non-limiting nutrient - and access only part of the nutrients available in the environment. We apply our model to the oceanic cycles of iron and phosphorus to examine whether phytoplankton can regulate the concentrations of these key nutrients and how interactions between the two cycles affect their regulation efficiency. Our model predicts that autotrophs cannot efficiently regulate concentrations of the non-limiting nutrient. We show that changes in the supply of the limiting nutrient affect the concentrations of the non-limiting nutrient, and that the two nutrients vary in opposite directions. Our results suggest that interactions between biogeochemical cycles can result either in an increase or in a decrease in the regulation efficiency of nutrient concentrations, depending on whether the supplies of the limiting and non-limiting nutrients vary in the same or opposite directions due to anthropogenic activities.
\end{abstract}

\section{Introduction}

Biogeochemical cycles are heavily altered by anthropogenic activities at global scales due to climate change, rising atmospheric carbon dioxide and excess nutrient inputs (Denman et al., 2007; Canadell et al., 2010; Doney, 2010; Ciais et al., 2013). Supplies of key nutrients such as carbon, nitrogen, phosphorus and oxygen to terrestrial and marine biogeochemical cycles are heavily affected by agricultural activities, land-use change and burning of fossil fuels (Seitzinger et al., 2005; Gruber and Galloway, 2008; Bouwman et al., 2009). Given these massive alterations, it is critical to assess the extent to which biotic and abiotic processes can lead to regulation of biogeochemical cycles at global scales.

Biotic regulation of the Earth system is the subject of a longstanding debate, especially concerning the Gaia hypothesis, which assumes that organisms maintain environmental conditions in a habitable range through self-regulating feedback mechanisms (e.g. Lovelock and Margulis, 1974a,b; Margulis and Lovelock, 1974).

\footnotetext{
* Corresponding author. Present address: Institut Méditerranéen de Biodiversité et d'Ecologie marine et continentale (IMBE), Aix Marseille Université, CNRS, IRD, Avignon Université, Technopôle Arbois-Méditerranée, Bât. Villemin - BP 80, 13545 Aix-en-Provence Cedex 04, France. Tel.: +33 442908451.

E-mail address: annesophie.augueres@gmail.com (A.-S. Auguères).
}

By modifying their environment through resource consumption, metabolism and habitat modification, organisms create strong feedbacks with their local environment (Kylafis and Loreau, 2008, 2011). However, theses processes do not necessarily result in regulation of the global environment because resource access is generally limited in space due to physical or chemical barriers (e.g. Ruardij et al., 1997; Ostertag, 2001; Menge et al., 2008; Vitousek et al., 2010). For instance, in marine and other aquatic systems, physical resource access limitation is usually due to the presence of a pycnocline because of the warming of surface waters when solar radiation is high and vertical exchanges in the water column are low (Vallis, 2000). As photosynthetic activity depletes nutrients in the surface layer and the barrier of density limits water exchanges with deep waters (Falkowski and Oliver, 2007), most of the nutrients in the water column are inaccessible to phytoplankton.

Interactions between the geosphere, atmosphere and biosphere result in the coupling of biogeochemical cycles. For example, autotrophs, which use light to assimilate carbon dioxide and inorganic nutrients simultaneously, create a strong coupling between the biogeochemical cycles of key elements such as carbon, nitrogen and phosphorus as well as between these cycles and the global climate (Falkowski et al., 2000; Gruber and Galloway, 2008). Fossil-fuel combustion and food production release nitrous oxides and ammonia in the environment, which are deposited on the ground or in the water, thereby increasing the growth of plants 
Table 1

Parameters of the stoichiometric model.

\begin{tabular}{|c|c|c|}
\hline Symbol & Description & Units \\
\hline$\alpha$ & Fraction of the system that is accessible to organisms & \\
\hline$m$ & Mortality rate of autotrophic organisms (including grazing) & $\mathrm{yr}^{-1}$ \\
\hline$\mu$ & Maximum growth rate of autotrophic organisms & $\mathrm{yr}^{-1}$ \\
\hline$R$ & $\mathrm{~N}_{2}: \mathrm{N}_{1}$ ratio of autotrophs & \\
\hline$N_{H, n}$ & Half saturation constant of the growth of autotrophic organisms for the nutrient $n$ in accessible form & $\mu \mathrm{mol} \mathrm{m}^{-3}$ \\
\hline$\lambda_{\mathrm{n}}$ & Fraction of organic matter that is not recycled in nutrient $n$ & \\
\hline$r e c_{a, n}$ & Fraction of recycling of nutrient $n$ that occurs in the accessible pool & \\
\hline$k_{a, n}$ & Transfer rate of nutrient $n$ from the accessible to the inaccessible pool & $\mathrm{yr}^{-1}$ \\
\hline$k_{i, n}$ & Transfer rate of nutrient $n$ from the inaccessible to the accessible pool & $\mathrm{yr}^{-1}$ \\
\hline$S_{a, n}$ & Supply of nutrient $n$ to the accessible pool & $\mu \mathrm{mol} \mathrm{m}{ }^{-3} \mathrm{yr}^{-1}$ \\
\hline$S_{i, n}$ & Supply of nutrient $n$ to the inaccessible pool & $\mu \mathrm{mol} \mathrm{m}{ }^{-3} \mathrm{yr}^{-1}$ \\
\hline$q_{a, n}$ & Turnover rate of nutrient $n$ in the accessible pool & $\mathrm{yr}^{-1}$ \\
\hline$q_{i, n}$ & Turnover rate of nutrient $n$ in the inaccessible pool & $\mathrm{yr}^{-1}$ \\
\hline
\end{tabular}

or phytoplankton and their uptake of atmospheric carbon dioxide (Gruber and Galloway, 2008).

Redfield ratios in the ocean provide one potential example of biotic regulation of the global environment that implies interactions between nutrient cycles (Auguères and Loreau, 2015a). Analysis of the composition of phytoplankton cells shows a mean $\mathrm{N}: \mathrm{P}$ ratio of $16 \mathrm{~N}: 1 \mathrm{P}$ (Redfield, 1934; Fleming, 1940), similar to the $\mathrm{N}: \mathrm{P}$ ratio of $15 \mathrm{~N}: 1 \mathrm{P}$ in deep waters obtained through the analysis of seawater samples (Redfield, 1934, 1958). The N:P ratio of deep waters can differ from the Redfield ratio due to changes in the N:P ratio of the material that is supplied to the ocean and in microbial activity, e.g. anammox (i.e. microbial process of anaerobic ammonium oxidation which releases $\mathrm{N}_{2}$ ), denitrification and nitrogen fixation (Gruber and Sarmiento, 1997; Karl, 1999; Karl et al., 2001; Arrigo, 2005). The diversity of phytoplankton communities and their spatial distribution can also create regional deviations from the Redfield ratio in deep waters (Weber and Deutsch, 2010; Weber and Deutsch, 2012). However, the deep-water N:P ratio seems to be almost constant over space and time, which suggests that biotic processes such as nitrogen fixation and denitrification control the proportions of N and P in seawater (Redfield, 1958; Tyrrell, 1999; Lenton and Klausmeier, 2007; Weber and Deutsch, 2010; Weber and Deutsch, 2012; Auguères and Loreau, 2015a).

Previous theoretical studies on biotic regulation of biogeochemical cycles have focused on regulation of the concentration of a single limiting nutrient (Auguères and Loreau, 2015b), or of the concentrations of two nutrients that limit the growth of two functional groups of organisms (e.g. Tyrrell, 1999; Lenton and Watson, 2000; Auguères and Loreau, 2015b). The ability of autotrophs to regulate nutrient concentrations in their environment, however, should be different for limiting and non-limiting nutrients. Interactions between nutrient cycles can also alter the concentration of nutrients in the environment, and thus their regulation by organisms. Our goal in this work is thus to elucidate the ability of autotrophs to regulate the pools of non-limiting nutrients in both accessible and inaccessible form at large spatial and temporal scales, as well as the interactions between the cycles of a limiting nutrient and a non-limiting one. We first develop and analyse a stoichiometric model of resource regulation with resource access limitation. Contrary to models applied to Redfield ratios in the ocean (e.g. Tyrrell, 1999; Lenton and Watson, 2000; Auguères and Loreau, 2015b), our model describes the dynamics of a single population of autotrophs. Both inorganic nutrients - one of which is limiting and the other is non-limiting for the growth of autotrophs - occur in two pools, one accessible and the other inaccessible to autotrophs. We then apply our model to the specific case of the regulation of iron (Fe) and phosphorus $(\mathrm{P})$ in the global ocean. We parameterise our model of coupled $\mathrm{P}$ and Fe cycles with existing data, and analyse the potential for biotic regulation of Fe and $\mathrm{P}$ concentrations as well as their ratio with respect to changes in the supply of both Fe and P. This case study is of special interest since Fe and P often limit phytoplankton growth (Moore et al., 2001; Moore and Doney, 2007; Moutin et al., 2008; Monteiro et al., 2011), and their supply to the surface ocean is heavily impacted by human activities (Benitez-Nelson, 2000; Mahowald et al., 2005; Krishnamurthy et al., 2010).

\section{Materials and methods}

We extend a previous model of resource regulation with resource access limitation (Auguères and Loreau, 2015b) to the biogeochemical cycles of two nutrients. In this model, nutrients occur in two pools, one that is accessible to autotrophs, and the other that is inaccessible to them, because of either physical or chemical barriers. $N_{a, 1}$ and $N_{a, 2}$ are the concentrations of nutrients 1 and 2, respectively, in the accessible pool. $N_{i, 1}$ and $N_{i, 2}$ are their concentrations in the inaccessible pool. Autotrophs, whose concentration in the accessible pool is $B$, consume nutrients in that pool. To differentiate the characteristics of the two nutrient cycles, we add a subscript corresponding to the nutrient considered (i.e. 1 or 2 ) to all the variables and parameters described in Auguères and Loreau (2015b). Model parameters are described in Table 1. The only parameter that is specific to the present stoichiometric extension of the model is the stoichiometric ratio of autotrophs $(R)$, i.e. the ratio of nutrient 2 to nutrient 1 in autotrophs. For the sake of simplicity, this stoichiometric ratio is supposed to be constant. The fraction $\alpha$ of the total volume of the system (i.e. the sum of the volumes of both accessible and inaccessible pools, noted $V_{a}+V_{i}$ ) that is accessible to organisms is supposed to be the same for both nutrients. This assumption, which we make for the sake of simplicity, should hold in the case of physical limitation, where physical barriers usually constrain the accessibility of all the nutrients in the same way. In the case of chemical limitation, the accessible and inaccessible forms of each nutrient occur in the same volume (i.e. $\left.V_{a}=V_{i}\right)$, and thus $\alpha=V_{a} /\left(V_{a}+V_{i}\right)=0.5$ for both nutrients.

The principle of mass balance is used to build a model that describes nutrient masses in each pool. By dividing nutrient mass by the volume of the pool concerned, we then obtain a model in terms of nutrient concentrations (Fig. 1):

$$
\begin{aligned}
& \frac{d N_{a, 1}}{d t}=S_{a, 1}-\left(k_{a, 1}+q_{a, 1}\right) N_{a, 1}+\frac{1-\alpha}{\alpha} k_{i, 1} N_{i, 1}+\left(\operatorname{mrec}_{1}\left(1-\lambda_{1}\right)-G\right) B \\
& \frac{d N_{a, 2}}{d t}=S_{a, 2}-\left(k_{a, 2}+q_{a, 2}\right) N_{a, 2}+\frac{1-\alpha}{\alpha} k_{i, 2} N_{i, 2}+\left(\operatorname{mrec}_{2}\left(1-\lambda_{2}\right)-G\right) R B \\
& \frac{d N_{i, 1}}{d t}=S_{i, 1}+\frac{\alpha}{1-\alpha} k_{a, 1} N_{a, 1}-\left(k_{i, 1}+q_{i, 1}\right) N_{i, 1}+\frac{\alpha}{1-\alpha} m\left(1-\operatorname{rec}_{1}\right)\left(1-\lambda_{1}\right) B \\
& \frac{d N_{i, 2}}{d t}=S_{i, 2}+\frac{\alpha}{1-\alpha} k_{a, 2} N_{a, 2}-\left(k_{i, 2}+q_{i, 2}\right) N_{i, 2}+\frac{\alpha}{1-\alpha} m\left(1-\operatorname{rec}_{2}\right)\left(1-\lambda_{2}\right) R B \\
& \frac{d B}{d t}=(G-m) B
\end{aligned}
$$




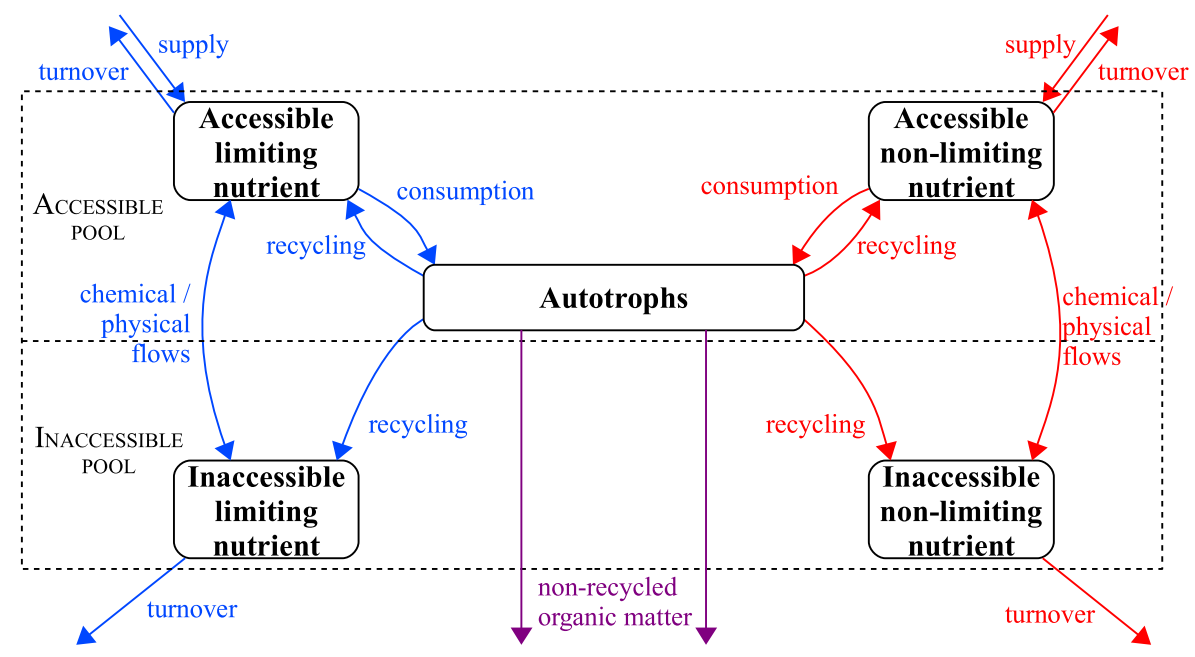

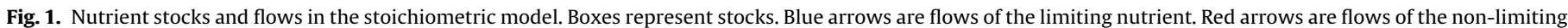

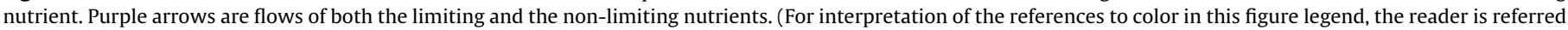
to the web version of the article.)

We assume that Liebig's (1842) law of the minimum governs the growth of organisms $(G)$ :

$G=\min \left(g_{1}\left(N_{a, 1}\right), g_{2}\left(N_{a, 2}\right)\right)$

where $g_{1}$ and $g_{2}$ are the functional responses of autotrophs to the concentration of $N_{a, 1}$ and $N_{a, 2}$, respectively.

We measure the strength of the regulation of the concentrations of either nutrient with respect to changes in the supply of that nutrient by calculating the regulation coefficient $\rho_{j x, j y}$ as one minus the elasticity of the equilibrium nutrient $j$ concentration in pool $x$ with respect to its supply to pool $y$ (Auguères and Loreau, 2015b):

$\rho_{j x, j y}=1-\frac{S_{j, y}}{N_{j, x}} \times \frac{\partial N_{j, x}}{\partial S_{j, y}}$

$\rho_{j x, j y}$ is defined as the regulation coefficient of the concentration of nutrient $j$ in pool $x$ with respect to changes its supply to pool $y$. When $\rho_{j x, j y}=0$, there is no regulation. At the other extreme, when $\rho_{j x, j y}=1$, regulation is perfect. Note that we calculate the regulation coefficient for the nutrient concentration at equilibrium; thus perfect regulation does not exclude variations in the nutrient concentration during transient dynamics. When $0<\rho_{j x, j y}<1$, regulation is partial. Autotrophs can sometimes over-regulate the nutrient $j$ concentration in pool $x$, in which case $\rho_{j x, j y}>1$. Some cases where $\rho_{j x, j y}<0$ can also occur; regulation is then negative, i.e. organisms amplify variations in nutrient supply.

We also quantify the effect of changes in the supply of one nutrient on the concentrations of the other using the following equation:

$\epsilon_{k x, j y}=\frac{S_{j, y}}{N_{k, x}} \times \frac{\partial N_{k, x}}{\partial S_{j, y}}$

$\varepsilon_{k x, j y}$ measures the effect of the supply of nutrient $N_{j}$ in pool $y$ on the concentration of nutrient $N_{k}$ in pool $x$. This effect is positive when the supply of $N_{j}$ in pool $y$ and the concentration of $N_{k}$ in pool $x$ vary in the same direction, negative when they vary in opposite directions, and zero when the supply of $N_{j}$ in pool $y$ does not affect the concentration of $N_{k, x}$.

We further quantify the strength of the regulation of the ratio between the two nutrients using the same principle as in Eq. (3). In this case, however, the elasticity of the ratio will change sign depending on whether the nutrient whose supply changes is in the numerator or in the denominator of the ratio. Therefore, to keep signs consistent, we calculate the regulation coefficient of $N_{1, x}: N_{2, x}$ ratio when the supply of $N_{1}$ is modified in either the accessible or the inaccessible pool, and the regulation coefficient of $N_{2, x}: N_{1, x}$ ratio when the supply of $N_{2}$ was modified. We obtain the following regulation coefficients for the nutrient ratio in pool $x$ :

$\rho_{\left(N_{1}: N_{2}\right) x, 1 y}=\rho_{1 x, 1 y}+\epsilon_{2 x, 1 y}$

$\rho_{\left(N_{2}: N_{1}\right) x, 2 y}=\rho_{2 x, 2 y}+\epsilon_{1 x, 2 y}$

To illustrate the general predictions of our model, we apply our model to the biogeochemical cycles of iron and phosphorus in the global ocean. This example corresponds to physical resource access limitation (Vallis, 2000). Note that in the oceanic Fe and $\mathrm{P}$ cycles, the supply of dissolved phosphorus and iron to the deep ocean is negligible at the scale of the global ocean (i.e. $S_{i, F e}=S_{i, P}=0$, Benitez-Nelson, 2000; Boyd and Ellwood, 2010). Thus, only the regulation of nutrient pools with respect to changes in the supply to the surface ocean is studied in numerical simulations.

In numerical simulations, the functional response of phytoplankton to an accessible nutrient is modelled with a Michaelis-Menten function:

$$
\begin{aligned}
& g_{1}\left(N_{a, 1}\right)=\frac{\mu N_{a, 1}}{N_{a, 1}+N_{H, 1}} \\
& g_{2}\left(N_{a, 2}\right)=\frac{\mu N_{a, 2}}{N_{a, 2}+N_{H, 2}}
\end{aligned}
$$

where $\mu$ is the maximal growth rate of phytoplankton, and $N_{H, 1}$ and $N_{H, 2}$ are the half-saturation constants for the accessible form of nutrients $N_{1}$ and $N_{2}$, respectively.

To perform numerical simulations, we chose parameter values within the range of values found in the literature (Table A1) in order to be as realistic as possible. We increased nutrient supply by $50 \%$ after one third of the simulation time to assess the strength of the regulation of $\mathrm{Fe}$ and $\mathrm{P}$ pools in the present ocean, in agreement with current trends due to anthropogenic activities (Bouwman et al., 2009; Boyd et al., 2010). A sensitivity analysis was performed to assess the sensitivity of results from numerical simulations to parameter values (Appendix A2). 


\section{Results}

Model (1) has three equilibria, depending on the presence or absence of organisms and the nutrient that limits their growth. In the absence of autotrophs, equilibrium concentrations (denoted by a - superscript) are:

$N_{a, 1}^{-}=\frac{S_{a, 1} \alpha\left(k_{i, 1}+q_{i, 1}\right)+k_{i, 1} S_{i, 1}(1-\alpha)}{\alpha\left[q_{a, 1}\left(k_{i, 1}+q_{i, 1}\right)+k_{a, 1} q_{i, 1}\right]}$

$N_{a, 2}^{-}=\frac{S_{a, 2} \alpha\left(k_{i, 2}+q_{i, 2}\right)+k_{i, 2} S_{i, 2}(1-\alpha)}{\alpha\left[q_{a, 2}\left(k_{i, 2}+q_{i, 2}\right)+k_{a, 2} q_{i, 2}\right]}$

$N_{i, 1}^{-}=\frac{S_{i, 1}(1-\alpha)+k_{a, 1} \alpha N_{a, 1}^{-}}{(1-\alpha)\left(k_{i, 1}+q_{i, 1}\right)}$

$N_{i, 2}^{-}=\frac{S_{i, 2}(1-\alpha)+k_{a, 2} \alpha N_{a, 2}^{-}}{(1-\alpha)\left(k_{i, 2}+q_{i, 2}\right)}$

$B^{-}=0$

In the absence of autotrophs, the concentrations of nutrient $i$ are partially regulated with respect to changes in its supply to both the accessible and inaccessible pools (i.e. $0<\rho_{i x, i y}<1$ ) because of chemical and physical processes. As autotrophs are absent, the cycles of nutrients 1 and 2 are independent of each other and thus there is no effect of changes in the supply of nutrient $i$ on the concentrations of nutrient $j$ (i.e. $\varepsilon_{i x, i y}=0$, where $i \neq j$ ).

In the presence of autotrophs, there are two equilibria depending on which nutrient limits the growth of autotrophs. Without loss of generality, we will focus on the case where nutrient 1 is the limiting nutrient and nutrient 2 is the non-limiting one.



Fig. 2. Regulation processes in the stoichiometric model. Bold arrows indicate a direct relationship (e.g. an increase in the concentration of the accessible limiting nutrient results in an increase in the biomass of autotrophs). Dashed arrows indicate an inverse relationship (e.g. an increase in the biomass of autotrophs results in a decrease in nutrient concentration in the accessible pool).

the same direction as supplies (paths $6 a-8$ and $6 b-8$ in Fig. 2; $\rho_{2 a, 2 a}=-0.72$ and $\rho_{2 i, 2 a}=-0.15$ in Fig. 3e, respectively). The absence of a negative feedback loop between autotrophs and the concentration of the non-limiting nutrient in the accessible pool prevents

$N_{a, 1}^{+}=g^{-1}(m)$

$N_{a, 2}^{+}=\frac{\alpha S_{a, 2}\left(k_{i, 2}+q_{i, 2}\right)+k_{i, 2} S_{i, 2}(1-\alpha)-\alpha m R B^{+}\left[q_{i, 2}\left(1-\operatorname{rec}_{2}\left(1-\lambda_{2}\right)\right)+k_{i, 2} \lambda_{2}\right]}{\alpha_{2}\left[\left(k_{a, 2}+q_{a 2}\right)\left(k_{i, 2}+q_{i, 2}\right)-k_{a, 2} k_{i, 2}\right]}$

$N_{i, 1}^{+}=\frac{-\left[\alpha k_{a, 1} N_{a, 1}^{+}+S_{i, 1}(1-\alpha)\right]\left[1-\operatorname{rec}_{1}\left(1-\lambda_{1}\right)\right]+\alpha\left(1-\operatorname{rec}_{1}\right)\left(1-\lambda_{1}\right)\left[-S_{a, 1}+N_{a, 1}+\left(k_{a, 1}+q_{a, 1}\right)\right]}{(1-\alpha)\left\{k_{i, 1}\left(1-\operatorname{rec}_{1}\right)\left(1-\lambda_{1}\right)-\left(k_{i, 1}+q_{i, 1}\right)\left[1-\operatorname{rec}_{1}\left(1-\lambda_{1}\right)\right]\right\}}$

$N_{i, 2}^{+}=\frac{\alpha_{1}\left[-S_{a, 2}+N_{a, 2}^{+}\left(k_{a, 2}+q_{a 2}\right)+m R B^{+}\left(1-\operatorname{rec}_{2}\left(1-\lambda_{2}\right)\right)\right]}{k_{i, 2}\left(1-\alpha_{1}\right)}$

$B^{+}=\frac{-S_{a, 1} \alpha\left(k_{i, 1}+q_{i, 1}\right)-k_{i, 1} S_{i, 1}(1-\alpha)+\alpha N_{a, 1}^{+}\left[q_{a, 1}\left(k_{i, 1}+q_{i, 1}\right)+k_{a, 1} q_{i, 1}\right]}{\alpha m\left\{k_{i, 1}\left(1-\operatorname{rec}_{1}\right)\left(1-\lambda_{1}\right)-\left(k_{i, 1}+q_{i, 1}\right)\left[1-\operatorname{rec}_{1}\left(1-\lambda_{1}\right)\right]\right\}}$

The nutrient concentrations, existence conditions, regulation coefficients within a cycle, and effects of a cycle on the other are detailed in Appendix A1 for each equilibrium. An analysis of the flows between nutrient pools helps to better understand the results (Fig. 2).

Results for the limiting nutrient are similar to those obtained with the generic model with a single nutrient (Auguères and Loreau, $2015 b$ ). In the presence of organisms, any variation in the supply of the accessible limiting nutrient is entirely absorbed by organisms because of their top-down control on the accessible pool of the limiting nutrient (negative feedback loop between autotrophs and the accessible pool, path 2-3 in Fig. 2), and thus $\rho_{1 a, 1 a}=\rho_{1 a, 1 i}=1$ $\left(\rho_{1 a, 1 a}=1\right.$ in Fig. $\left.3 a\right)$. The concentration of the limiting nutrient in the inaccessible pool is only partially or negatively regulated with respect to changes in its supply because it varies in the same direction as the supply of nutrient in both accessible and inaccessible forms (paths $1 \mathrm{a}-4,1 \mathrm{a}-2-5$ and $1 \mathrm{~b}-4-2-5$ in Fig. $2 ; \rho_{1 i, 1 a}=0.20$ in Fig. 3a). Changes in the supply of the non-limiting nutrient in either pool have no effect on the limiting nutrient pools because they do not affect biomass (no arrow from the non-limiting nutrient concentrations to biomass in Fig. 2); thus $\varepsilon_{1 a, 2 a}=\varepsilon_{1 a, 2 i}=\varepsilon_{1 i, 2 a}=\varepsilon_{1 i, 2 i}=0$ $\left(\varepsilon_{1 a, 2 a}=\varepsilon_{1 i, 2 a}=0\right.$ in Fig. $\left.3 \mathrm{~d}\right)$.

Changes in the supply of the non-limiting nutrient are either partially or negatively regulated because concentrations vary in autotrophs from regulating the concentrations of the non-limiting nutrient (Fig. 2). Changes in the supplies of the limiting nutrient have a negative effect on the concentrations of the non-limiting nutrient. Concentrations of the non-limiting nutrient and the supply of the limiting nutrient indeed vary in the opposite direction (paths 1a-2-7, 1a-2-7-8, 1b-4-2-7 and 1b-4-2-7-8 in Fig. 2). This result is intuitive as an increase in the supply of the limiting nutrient enhances the growth of autotrophs, then resulting to an increase in the depletion of the non-limiting nutrient pools. Thus, in the example of $\mathrm{P}$ and Fe oceanic cycles, the increase in Fe concentration results in a decrease in $\mathrm{P}$ concentrations in both the surface and deep layers $\left(\varepsilon_{2 a, 1 a}=-0.79\right.$ and $\varepsilon_{2 i, 1 a}=-0.16$ in Fig. $3 \mathrm{~b}$ ).

In this paragraph, we will focus on regulation of the ratio of the limiting nutrient over the non-limiting one with respect to changes in the supplies of each nutrient. When supplies of the limiting nutrient vary, accessible concentration of the limiting nutrient is perfectly regulated, while that of the nonlimiting nutrient is partially or negatively regulated. Thus the nutrient ratio is either partially or negatively regulated in the accessible pool $\left(\rho_{\left(N_{1}: N_{2}\right) a, 1 a}=0.21\right.$ and $\rho_{\left(N_{2}: N_{1}\right) a, 2 a}=-0.72$ in Fig. $3 c$ and $f$, respectively). Regulation of the nutrient ratio in the inaccessible pool, however, depends on the relative changes in the concentrations of the two nutrients as a result of variations in 

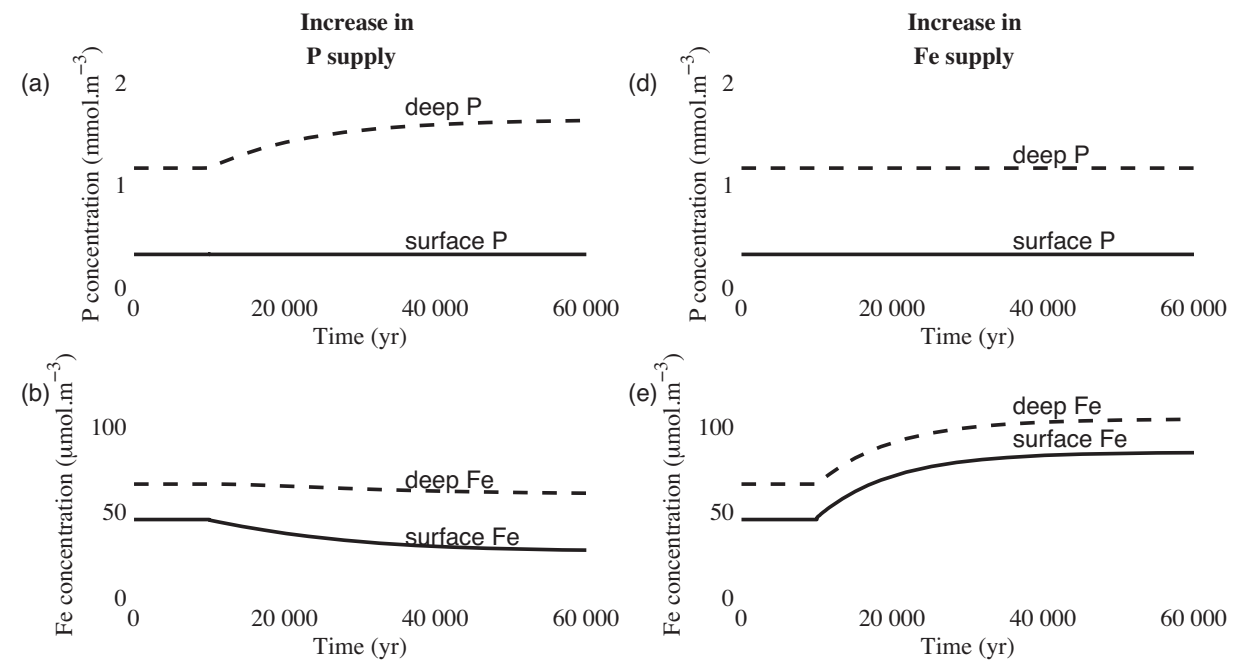

(c) 40

(f) 40


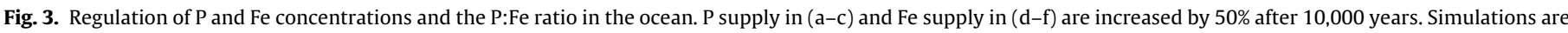

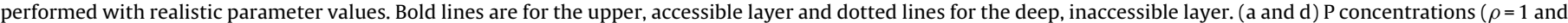



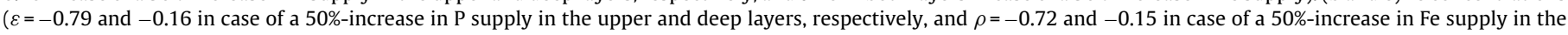

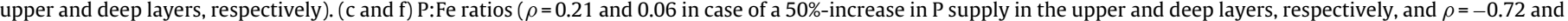
-0.15 in case of a $50 \%$-increase in Fe supply in the upper and deep layers, respectively).

the supply of the limiting nutrient $\left(\rho_{\left(N_{1}: N_{2}\right) i, 1 a}=0.04\right.$ in Fig. $\left.3 \mathrm{c}\right)$. Nutrient ratio is either partially or negatively regulated with respect to changes in the supply of the non-limiting nutrient in both the accessible and the inaccessible pools, because variations in the supplies of the non-limiting nutrient do not affect the concentration of the limiting nutrient $\left(\rho_{\left(N_{2}: N_{1}\right) i, 2 a}=-0.15\right.$ in Fig. $\left.3 f\right)$.

\section{Discussion}

Our model predicts that autotrophic organisms should only partially or negatively regulate the concentrations of a non-limiting nutrient. Thus, explicit consideration of the cycle of a non-limiting nutrient suggests that autotrophs have limited ability to regulate global biogeochemical cycles. Regulation can switch from partial to negative, depending on the parameter values. For example, in the case of an increase in the supply of the non-limiting nutrient to the inaccessible pool $\left(S_{i, 2}\right)$, strongly reducing the turnover rate of the non-limiting nutrient in the inaccessible pool $\left(q_{i, 2}\right)$ will result in an accumulation of the non-limiting nutrient in the inaccessible pool. The relative increase in the nutrient concentration in the inaccessible pool can then become greater than the relative increase in the non-limiting nutrient supply, resulting in a negative regulation of the inaccessible non-limiting nutrient concentration $\left(\rho_{2 i, 2 i}<0\right)$.

Variations in the supply of a non-limiting nutrient do not affect the growth of autotrophs, and thus they do not affect the concentrations of the limiting nutrient in either the accessible or the inaccessible pool. Variations in the supply of the limiting nutrient, however, affect the growth of autotrophs and their consumption of non-limiting nutrients. As a result, variations in the supply of the limiting nutrient and concentrations of non-limiting nutrients vary in opposite directions. For example, if the supply of the limiting nutrient increases, depletion of the accessible non-limiting nutrient increases, resulting in a decrease in both the accessible and inaccessible concentrations of the non-limiting nutrient. If the supply of the non-limiting nutrient is also increased, the effects of the increased supply of the two nutrients will partly counterbalance each other, and thus the global regulation of the non-limiting nutrient will be enhanced by interactions between cycles. In contrast, if the supply of the non-limiting nutrient is decreased, it will further amplify the decrease in the concentration of the non-limiting nutrient induced by the increased supply of the limiting nutrient. Our model thus suggests that interactions between biogeochemical cycles can either (1) decrease the ability of autotrophs to regulate non-limiting nutrient pools if the supplies of the limiting and the non-limiting nutrients vary in opposite directions, or (2) increase the ability of autotrophs to regulate non-limiting nutrient pools if the supplies of the limiting and the non-limiting nutrients vary in the same direction. In the case study of Fe and $\mathrm{P}$ oceanic cycles, interactions between the two cycles should thus enhance the regulation of P concentrations, as the supplies of both nutrients are increased by anthropogenic activities. In contrast, the supply of some nutrients such as $\mathrm{Si}$ is decreased by human activities (Laruelle et al., 2009), and thus the regulation of Si oceanic pools should be decreased by interactions between the oceanic cycles of Si and the nutrient that limits phytoplankton growth, e.g. Fe or P.

The inaccessibility of part of resources can severely constrain the efficiency of biotic regulation of global biogeochemical cycles of both limiting and non-limiting nutrients. But a wide range of processes can affect the strength of biotic regulation. Even though the regulation of nutrient pools is expected to be weak, our results are not incompatible with previous results showing a strong regulation by organisms of the ratio of chemical elements in their environment (Lovelock and Margulis, 1974a,b; Lenton, 2001; Auguères and 
Loreau, 2015a). Other processes than resource consumption and coupling of biogeochemical cycles can also affect the ability of organisms to regulate their environment through either negative (e.g. between oxygen concentration and fire frequency, Lenton, 2001) or positive (e.g. between the $\mathrm{CO}_{2}$ concentration and its dissolution capacity in seawater, Denman et al., 2007) feedback mechanisms.

In our model, we assumed that Liebig's (1842) law of the minimum governs the growth of autotrophs, and hence that the latter is limited by the supply of the most limiting nutrient. Colimitation of autotrophs by two or more nutrients simultaneously, however, is common in natural systems (Arrigo, 2005; Sterner, 2008; Harpole et al., 2011). When there is colimitation by two nutrients, changes in the supply of both nutrients affect the growth of autotrophs (Sperfeld et al., 2012). The increase in the supply of the less limiting nutrient will enhance the growth of autotrophs, thereby increasing the depletion of both nutrients. Colimitation is thus likely to enhance regulation of the concentrations of the less limiting nutrient. But variations in the growth of autotrophs also affect the consumption of the more limiting nutrient, which was not the case with limitation by a single nutrient. Thus, colimitation is likely to increase biotic regulation of the less limiting nutrient but to decrease that of the more limiting one.

The ability of autotrophs to adapt their stoichiometry depending on nutrient availability can also alter the control of autotrophs on nutrient cycles. Variable stoichiometry of autotrophs can indeed change the patterns of nutrient limitation, and hence the consumption and control of resources (Sterner and Elser, 2002; Danger et al., 2008). Consumer-driven nutrient recycling (i.e. the release of part of the nutrients ingested by herbivores in the environment) is a major process affecting the availability of nutrients in the environment, which potentially modifies the limitation conditions of the growth of autotrophs. For example, zooplankton can affect the availability of nutrients in surface and deep waters through vertical migrations and excretion of part of the nutrients ingested (Elser and Urabe, 1999; Palmer and Totterdell, 2001; Thingstad et al., 2005). This can result in a shift from $\mathrm{P}$ or $\mathrm{N}$ limitation of autotroph growth to colimitation by the two nutrients simultaneously in freshwater and marine ecosystems (Moegenburg and Vanni, 1991; Trommer et al., 2012). However, consumer-driven nutrient recycling does not necessarily have a positive effect on the growth of autotrophs (Daufresne and Loreau, 2001), and thus on biotic regulation of biogeochemical cycles. A useful extension of our model could thus be the explicit consideration of herbivores. However, a major issue in assessing the effects of herbivores on the regulation of global biogeochemical cycles is the choice of the functional response that determines consumption of autotrophs by herbivores (Gentleman et al., 2003). Functional responses are known to depend on scale, and it is difficult to know which formulation is best adapted to global scales (Englund and Leonardsson, 2008). For example, donor-controlled herbivory (i.e. herbivores consume a constant proportion of the autotroph population, independently of their own biomass) does not alter the top-down control of autotrophs on the inorganic limiting nutrient, whereas recipient-controlled herbivory (i.e. the consumption of autotrophs by herbivores depends on the biomass of both populations, leading to top-down control at equilibrium) results in a control of the system by herbivores instead of autotrophs. Thus, the effect of herbivory on biotic regulation of global biogeochemical cycles is likely to strongly depend on the type of functional response used.

In our model, we considered a single population of autotrophs. Competition between populations of autotrophs with different stoichiometric ratios and/or competition between different functional groups could, however, alter our results. For example, our model predicts that nutrient ratios should be either partially or negatively regulated against changes in the supplies of both the limiting and the non-limiting nutrients. However, observations and theory show that regulation of the ratio of inaccessible nutrients can be high even though regulation of their concentrations is limited, as it is the case with Redfield ratios in the ocean (Redfield, 1934, 1958; Falkowski et al., 2000; Gruber and Deutsch, 2014; Auguères and Loreau, 2015a). To be applied to the oceanic cycles of $\mathrm{N}$ and $\mathrm{P}$, our stoichiometric model can be extended to describe the dynamics of two functional groups of autotrophs, i.e. non-fixers and N-fixers (e.g. Tyrrell, 1999; Lenton and Watson, 2000), and study the regulation of deep-water $\mathrm{N}$ :P ratio by autotrophs, This extended model predicts that the compensatory dynamics between the two functional groups of autotrophs enhances the ability of autotrophs to regulate nutrient ratios, but not their concentrations (Auguères and Loreau, 2015a).

Note, however, that these studies of Redfield ratios in the ocean assume that $\mathrm{N}$ limits the growth of non-fixers and $\mathrm{P}$ limits that of N-fixers (e.g. Tyrrell, 1999; Lenton and Watson, 2000; Auguères and Loreau, 2015a). Thus, they address the issue of the regulation of the ratio of two nutrients, each of which is limiting for a different functional group, but they do not really consider regulation of non-limiting nutrients. Our present stoichiometric model shows that the cycles of non-limiting nutrients can be heavily impacted by variations in both their supply and that of limiting nutrients, and therefore that considering the dynamics of non-limiting nutrients is critical to understand and predict the ability of organisms to regulate biogeochemical cycles.

\section{Acknowledgement}

This work was supported by the TULIP Laboratory of Excellence (ANR-10-LABX-41).

\section{Appendix A. Supplementary data}

Supplementary data associated with this article can be found, in the online version, at http://dx.doi.org/10.1016/j.ecolmodel.2016. 04.016.

\section{References}

Arrigo, K.R., 2005. Marine microorganisms and global nutrient cycles. Nature 437, 349-355.

Auguères, A.-S., Loreau, M., 2015a. Can organisms regulate global biogeochemical cycles? Ecosystems, 1-13

Auguères, A.-S., Loreau, M., 2015b. Regulation of Redfield ratios in the deep ocean. Global Biogeochem. Cycles 29, 254-266.

Benitez-Nelson, C.R., 2000. The biogeochemical cycling of phosphorus in marine systems. Earth Sci. Rev. 51, 109-135.

Bouwman, A.F., Beusen, A.H.W., Billen, G., 2009. Human alteration of the global nitrogen and phosphorus soil balances for the period 1970-2050. Global Biogeochem. Cycles 23, GB0A04

Boyd, P.W., Ellwood, M.J., 2010. The biogeochemical cycle of iron in the ocean. Nat. Geosci. 3, 675-682.

Boyd, P.W., Mackie, D.S., Hunter, K.A., 2010. Aerosol iron deposition to the surface ocean - modes of iron supply and biological responses. Mar. Chem. 120, $128-143$.

Canadell, J.G., Ciais, P., Dhakal, S., et al., 2010. Interactions of the carbon cycle, human activity, and the climate system: a research portfolio. Curr. Opin. Environ. Sustain. 2, 301-311.

Ciais, P., Sabine, C., Bala, G., et al., 2013. Carbon and other biogeochemical cycles. In: Climate Change 2013: The Physical Science Basis. Contribution of Working Group I to the Fifth Assessment Report of the Intergovernmental Panel on Climate Change. Cambridge University Press, pp. 465-570.

Danger, M., Daufresne, T., Lucas, F., et al., 2008. Does Liebig's law of the minimum scale up from species to communities? Oikos 117, 1741-1751.

Daufresne, T., Loreau, M., 2001. Plant-herbivore interactions and ecological stoichiometry: when do herbivores determine plant nutrient limitation? Ecol. Lett. 4, 196-206.

Denman, K.L., Brasseur, G., Chidthaisong, A., et al., 2007. Couplings between changes in the climate system and biogeochemistry. In: Solomon, S., Qin, D., Manning, M. (Eds.), Climate Change 2007: The Physical Science Basis. Contribution of Working Group I to the Fourth Assessment Report of the Intergovernmental Panel on Climate Change. Cambridge University Press, Cambridge, United Kingdom/New York, NY, USA. 
Doney, S.C., 2010. The growing human footprint on coastal and open-ocean biogeochemistry. Science 328, 1512-1516.

Elser, J.J., Urabe, J., 1999. The stoichiometry of consumer-driven nutrient recycling: theory, observations, and consequences. Ecology 80, 735-751.

Englund, G., Leonardsson, K., 2008. Scaling up the functional response for spatially heterogeneous systems. Ecol. Lett. 11, 440-449.

Falkowski, P.G., Oliver, M.J., 2007. Mix and match: how climate selects phytoplankton. Nat. Rev. Microbiol. 5, 813-819.

Falkowski, P., Scholes, R.J., Boyle, E., et al., 2000. The global carbon cycle: a test of our knowledge of Earth as a system. Science 290, 291-296.

Fleming, R., 1940. The composition of plankton and units for reporting populations and production. Proc. Sixth Pac. Sci. Congr. Calif. 1939 (3), 535-540.

Gentleman, W., Leising, A., Frost, B., et al., 2003. Functional responses for zooplankton feeding on multiple resources: a review of assumptions and biological dynamics. Deep Sea Res. 2 (50), 2847-2875.

Gruber, N., Deutsch, C.A., 2014. Redfield's evolving legacy. Nat. Geosci. 7 $853-855$.

Gruber, N., Galloway, J.N., 2008. An earth-system perspective of the global nitrogen cycle. Nature 451, 293-296.

Gruber, N., Sarmiento, J.L., 1997. Global patterns of marine nitrogen fixation and denitrification. Global Biogeochem. Cycles 11, 235-266.

Harpole, W.S., Ngai, J.T., Cleland, E.E., et al., 2011. Nutrient co-limitation of primary producer communities. Ecol. Lett. 14, 852-862.

Karl, D., Dore, J., Lukas, R., et al., 2001. Building the long-term picture: the U.S. JGOFS time-series programs. Oceanography 14, 6-17.

Karl, D.M., 1999. A sea of change: biogeochemical variability in the North Pacific Subtropical Gyre. Ecosystems 2, 181-214

Krishnamurthy, A., Moore, J.K., Mahowald, N., et al., 2010. Impacts of atmospheric nutrient inputs on marine biogeochemistry. J. Geophys. Res. 115, G01006.

Kylafis, G., Loreau, M., 2008. Ecological and evolutionary consequences of niche construction for its agent. Ecol. Lett. 11, 1072-1081.

Kylafis, G., Loreau, M., 2011. Niche construction in the light of niche theory. Ecol. Lett. 14, 82-90.

Laruelle, G.G., Roubeix, V., Sferratore, A., et al., 2009. Anthropogenic perturbations of the silicon cycle at the global scale: key role of the land-ocean transition. Global Biogeochem. Cycles 23, GB4031.

Lenton, T.M., 2001. The role of land plants, phosphorus weathering and fire in the rise and regulation of atmospheric oxygen. Global Change Biol 7 , 613-629.

Lenton, T.M., Klausmeier, C.A., 2007. Biotic stoichiometric controls on the deep ocean N:P ratio. Biogeosciences 4, 353-367.

Lenton, T.M., Watson, A.J., 2000. Redfield revisited: 1. Regulation of nitrate, phosphate, and oxygen in the ocean. Global Biogeochem. Cycles 14, 225-248.

Lovelock, J.E., Margulis, L., 1974a. Atmospheric homeostasis by and for the biosphere: the gaia hypothesis. Tellus 26, 2-10.

Lovelock, J.E., Margulis, L., 1974b. Homeostatic tendencies of the Earth's atmosphere. In: Oró, J., Miller, S.L., Ponnamperuma, C., Young, R.S. (Eds.), Cosmochemical Evolution and the Origins of Life. Springer, Netherlands, pp. 93-103.

Mahowald, N.M., Baker, A.R., Bergametti, G., et al., 2005. Atmospheric global dust cycle and iron inputs to the ocean. Global Biogeochem. Cycles 19, GB4025.

Margulis, L., Lovelock, J.E., 1974. Biological modulation of the Earth's atmosphere. Icarus 21, 471-489.

Menge, D.N.L., Levin, S.A., Hedin, L.O., 2008. Evolutionary tradeoffs can select against nitrogen fixation and thereby maintain nitrogen limitation. Proc. Natl. Acad. Sci. U. S. A. 105, 1573-1578.
Moegenburg, S.M., Vanni, M.J., 1991. Nutrient regeneration by zooplankton: effects on nutrient limitation of phytoplankton in a eutrophic lake. J. Plankton Res. 13 $573-588$.

Monteiro, F.M., Dutkiewicz, S., Follows, M.J., 2011. Biogeographical controls on the marine nitrogen fixers. Global Biogeochem. Cycles 25, GB003902.

Moore, J.K., Doney, S.C., 2007. Iron availability limits the ocean nitrogen inventory stabilizing feedbacks between marine denitrification and nitrogen fixation. Global Biogeochem. Cycles 21, GB002762.

Moore, J.K., Doney, S.C., Glover, D.M., Fung, I.Y., 2001. Iron cycling and nutrient-limitation patterns in surface waters of the World Ocean. Deep Sea Res. 2 (49), 463-507.

Moutin, T., Karl, D.M., Duhamel, S., et al., 2008. Phosphate availability and the ultimate control of new nitrogen input by nitrogen fixation in the tropical Pacific Ocean. Biogeosciences 5, 95-109.

Ostertag, R., 2001. Effects of nitrogen and phosphorus availability on fine-root dynamics in Hawaiian Montane forests. Ecology 82, 485-499.

Palmer, J.R., Totterdell, I.J., 2001. Production and export in a global ocean ecosystem model. Deep Sea Res 1 (48), 1169-1198.

Redfield, A.C., 1934. On the proportions of organic derivations in sea water and their relation to the composition of plankton. In: Daniel, R.J. (Ed.), James Johnstone Memorial Volume. University Press of Liverpool, Liverpool, UK, pp. 177-192.

Redfield, A.C., 1958. The biological control of chemical factors in the environment. Am. Sci. 46, 205-221.

Ruardij, P., Van Haren, H., Ridderinkhof, H., 1997. The impact of thermal stratification on phytoplankton and nutrient dynamics in shelf seas: a model study. J. Sea Res. 38, 311-331.

Seitzinger, S.P., Harrison, J.A., Dumont, E., 2005. Sources and delivery of carbon, nitrogen, and phosphorus to the coastal zone: an overview of global Nutrient Export from Watersheds (NEWS) models and their application. Global Biogeochem. Cycles 19, GB4S01.

Sperfeld, E., Martin-Creuzburg, D., Wacker, A., 2012. Multiple resource limitation theory applied to herbivorous consumers: Liebig's minimum rule vs. interactive co-limitation. Ecol. Lett. 15, 142-150.

Sterner, R.W., 2008. On the phosphorus limitation paradigm for lakes. Int. Rev. Hydrobiol. 93, 433-445.

Sterner, R.W., Elser, J.J., 2002. Ecological Stoichiometry: The Biology of Elements from Molecules to the Biosphere. Princeton University Press, Princeton, USA

Thingstad, T.F., Krom, M.D., Mantoura, R.F.C., et al., 2005. Nature of phosphorus limitation in the ultraoligotrophic Eastern Mediterranean. Science 309, 1068-1071.

Trommer, G., Pondaven, P., Siccha, M., Stibor, H., 2012. Zooplankton-mediated nutrient limitation patterns in marine phytoplankton: an experimenta approach with natural communities. Mar. Ecol. Prog. Ser. 449, 83-94.

Tyrrell, T., 1999. The relative influences of nitrogen and phosphorus on oceanic primary production. Nature 400, 525-531.

Vallis, G.K., 2000. Large-scale circulation and production of stratification: effects of wind, geometry, and diffusion. J. Phys. Oceanogr. 30, 933-954.

Vitousek, P.M., Porder, S., Houlton, B.Z., Chadwick, O.A., 2010. Terrestrial phosphorus limitation: mechanisms, implications, and nitrogen-phosphorus interactions. Ecol. Appl. 20, 5-15.

Von Liebig, J.F., 1842. Chemistry and its Application to Agriculture and Physiology. John Owen, Cambridge.

Weber, T., Deutsch, C., 2012. Oceanic nitrogen reservoir regulated by plankton diversity and ocean circulation. Nature 489, 419-422.

Weber, T.S., Deutsch, C., 2010. Ocean nutrient ratios governed by plankton biogeography. Nature 467, 550-554. 